\title{
Assessment of Students' Performance in Physics Using Two Teaching Techniques
}

\author{
Alaba Tolulope Agbele ${ }^{1 *}$, Emmanuel Akinbami Oyelade ${ }^{2}$, Victor Shegun Oluwatuyi ${ }^{3}$ \\ ${ }^{1}$ Department of Basic Medical Sciences, College of Health Sciences and Technology Ijero-Ekiti, Ekiti State, Nigeria \\ ${ }^{2}$ Department of Science Education, Federal University of Lafia, Nasarawa State, Nigeria \\ ${ }^{3}$ Department of Public Health (Health Education), College of Health Sciences and Technology, Ijero-Ekiti, Ekiti, Nigeria \\ ${ }^{*}$ Corresponding author
}

\begin{abstract}
This study was conducted to assess the best teaching method of Physics in Ekiti State, Nigeria. The study used primary data which was collected by using "Students" Achievement Test" from fifty Senior Secondary School Two (SSS II) students of thirty males and twenty females, who were randomly selected in order to test the performance of students in Physics class. The data were analysed by using descriptive statistics and analytical technique. The researchers formulated and tested for hypotheses at $\mathbf{p}<0.05$ significant level.
\end{abstract}

The result of the data analysis showed that there is a significant difference between the mean score of students taught with collaborative method and traditional method. Results showed that collaborative inquiry method of teaching is far better than the traditional method. The study also revealed that the male students performed better in Physics as a science subject than their female counterparts.

The study thus recommended that students should be engaged in exploring, investigating and answering questions through the use of collaborative inquiry method so as to enhance a better performance in their learning process.

Keywords: Teaching techniques, Physics, Collaborative inquiry learning, Traditional method, Assessment, Students' performance

\section{INTRODUCTION}

$\mathrm{T}$ he concept of national development cannot be over emphasized in terms of the extent and sophistication of the materials and objects owned by a nation and its citizens. Ideally, people need food, shelter and clothing [1], however, the level of development of a nation if it has to be sustained beyond this generation, it should not only be measured in terms of its material wealth but should also reflect the ability and capability of its citizens to invent and innovate [2-4]. In so doing, such a nation is promoting development and at the same time it is concerned with both feeding the body and the mind [5].

In sciences, Physics form the fundamental basis for an argument or theory to other science subjects, technology and engineering [6]. Therefore, if we must produce good technologists, technology innovators as well as inventors, as a starting point, we need well-breed Physicists and Physics educators which begins right from the secondary schools. Also, the need to increase the number of Physics researchers and promoting greater collaboration amongst researchers will be of great importance in order to achieve a landmark [7]. The year 2001 report on Physics, claimed that: Physics is becoming a thoroughly global enterprise [8]. This transformation reflects on the increasing need for large, complex and expensive facilities for any single nation to build and it is largely a consequence of modern information and communication technology (ICT) which is the heart of the present age of change.

Physics requires a complete understanding of Mathematical language so as to get the full concepts involved. This requires a fluency in mathematical expressions and it must be understood by the students so as to achieve an optimum result, because these concepts in physics are expressed in mathematical terms [9]. However, it has been showed that in many introductory and algebra-based principles, Physics students perform poorly in mathematical problems. These can be attributed to:

a) Students' lack the understanding of the mathematical skills that is required in solving Physics related problems [9].

b) Students' lack the application of the basic principle of the mathematical skills in solving problem in Physics [8].

Students' poor performance in Physics as a result of lack of understanding of the mathematical skills required led to conceptual adoption of Physics [9], which dilutes mathematical problem solving or simply by removing it from the curriculum of study [10]. Over the years, there has been a lot of contributions to the development and advancement of science. Many scientists such as; Femmie Dirac, W. E. Lamb and R. C. Rutherford, just to mention a few, have contributed greatly to the development of Physics. Dirac discovered electron-pair by light quanta while the duo of Lamb and Rutherford clearly point out the possible understanding of interaction between protons and electrons.

Owing to the inevitable role of Physics in the nation's technological development, government at all levels had incorporated the subject in the school curriculum through the research reports of bodies like; National Science and Technology Development Agency (NSTDA), Nigeria Education Research Council (NERC) and Science Teachers' Association of Nigeria (STAN) among others. 
In understanding the teaching methodologies, there are four different types of inquiries Vis-à-vis:

a) Structured Inquiry: in a structured inquiry, a handson problem is being investigated by giving the students a procedure and learning materials but the students need not be informed of the expected outcomes.

b) Guided Inquiry: in guided inquiry, materials and problem are provided but the students' will have to find their own procedure.

c) Open Inquiry: open inquiry is similar to guided inquiry, the only difference is that the students will develop their own problem to be investigated.

d) Learning Inquiry: in learning inquiry, the students are being engaged in an activity that will introduce a new concept of learning [11].

\section{Government Efforts Toward Improving Achievement in Physics}

The Federal Government of Nigeria as well as the 36 States through the various Ministries of Education across the nation are concerned about how to improve the performance or achievement of Students in science especially Physics. The need was in order to develop Nigeria technologically in agriculture, electronics, industry, communication, engineering, and pharmaceuticals etc. This age-long efforts of the government at all levels brings about the idea of establishing institution of higher learning such as universities of science and technology, this has been reflecting in various governments activities in Ekiti State, Nigeria.

However, attention has been drawn to science education in Nigeria recently, especially at higher institution level through the award of scholarships in order to help the less privilege and encourage the students. This effort was geared towards the achievement of national objectives of Nigeria which says "education should be geared towards among other things, scientific and technical progress". The Secondary Education should also be given a priority so as to prepare the students to live up to expectation in the modern age of ICT, science and technology.

Alao [12] also supported the above facts when he quoted Babs Fafunwa saying: "science has become a necessary aid to good living and good citizenship to health, agriculture, home making and leisure". For these reasons therefore, it is evident that science and technology play an important role in the Nigerian education curriculum. Moreover, the core subject in the sciences i.e. "Physics" must be thoroughly taught in order to have a better achievement in technology.

Appelquist and Shapers [13] also attests to the fact that; Physics is a global enterprise which reflects an increase for large, complex and expensive systems for a nation to achieve as this is largely a factor to be considered in this modern era of ICT which is the heart of the present computer age. The report goes on to identify six "ground challenges" that torches all areas of Physics and overlap with other areas of science and engineering. These includes: development of quantum technologies, creating new materials, understanding complex systems, unifying the forces of nature, exploring the universe and applying Physics principles to Biology.

\section{Collaborative Learning}

Thornton [14] opined that: collaborative learning is based on the idea that learning is naturally a social act in which the participants talk among themselves. It is through the talk that learning processes take place. On the other hand, Negata and Ponkowski [15] said that; collaborative learning is the umbrella term encompassing many forms of collaborative learning from small group of projects to more specific form of group work called "collaborative learning".

Collaborative learning is very useful in completing of a group research project, in which team work is well appreciated. Furthermore, collaborative learning groups can be initiated for many reasons to get students engaged with subject matter in any discipline. This can be achieved online, in a laboratory setting, field work and even in the normal classroom settings. It is also possible to introduce a cross-curricular projectsinvolving; biologist, environmentalist, physicist and even a geneticist. This type of collaborations is required in many workplace projects which entails a multidisciplinary project. The type of project to be solved ranges from community projects to commerce and industry and the solution requires the use of knowledge, skills and attributes that are part of the curricula. The problem can be solved by a small team of students, none of whom possess the knowledge or skills to solve the problem alone, yet each of whom is able to contribute to the final product [16].

\section{Traditional Learning}

Herr [17] opined that "traditional teaching is concerned with the teacher being the controller of the learning environment". Power and responsibilities are held by the teacher and they play the role of an instructor (in the form of lecturer) and the decision maker as regards the content of the curriculum and its specific results. Students are regarded as having knowledge-holes which needs to be filled with the required and specific information. In the traditional teaching method, the teacher is seen as the person who causes the learning process to take place.

Johnson et al., [18] also stated that learning is critically associated with the classroom and it is often more competitive in nature. The contents of the lesson and the method of teaching are very important so that the student can master the knowledge-based via drill and practice.

\section{Statement of The Problem}

The method adopted in teaching Physics in the classroom setting has a long way to go in achieving the desired results. However, it is believed that collaborative inquiry method will be of greater advantage over the traditional teaching method 
in achieving a good performance in teaching and learning of Physics at the secondary school level.

\section{Research Hypotheses}

The research hypotheses are:

a) There is no statistically significant difference between the mean scores of students taught with collaborative and traditional teaching methods.

b) There is no statistically significant difference between the mean scores of male and female students exposed to the collaborative inquiry method.

\section{Significance of The Study}

This study gives sufficient information which serves as an insight into the teaching method to be adopted in the teaching of Physics in Senior Secondary Schools. The study would be of great benefit to the students in terms of; positive interdependence, individual accountability, group processing as well as face-to-face primitive interaction. Also this study would be of great advantage to the teachers and educators in determining the appropriate teaching techniques to be adopted in impacting knowledge on the students.

\section{MATERIALS AND METHODS}

The instrument used for data collection was "Students Achievement Test" (SAT) which comprised of twenty (20) objective (multi-choice) questions from the Physics syllabus. The purpose of this study is to experiment two different methods of teaching Physics in Ekiti State Senior Secondary Schools; then recommend the better method of the two teaching methods.

This study adopted only two teaching methods (collaborative inquiry and traditional teaching methods) on Senior Secondary School Two (SSS II) Students in Ekiti South West Local Government Area of Ekiti State. Two schools were selected in the Local Government area and the schools are:

a) Ilawe Grammar School, Ilawe-Ekiti.

b) Omoeleye Community Grammar School, Igbara Odo Ekiti

However, it is believed that the findings of the research would be of advantage to the teaching of Physics in other senior secondary school classes in the state and the nation at large.

\section{Procedure for Data Collection}

The researchers took permission from the principals and teachers of the selected schools, in order to carry out the research in the schools and on the students. Traditional method and collaborative teaching method were used to teach the students on the selected four (4) topics, and at the end of the lesson, the test items were distributed to the students and the researchers explained to the students' the procedure for answering the questions, using answer sheet to indicate their choice answer. The test was $100 \%$ monitored and supervised by the researchers. After the stipulated time given, the instrument was collected and used for data analysis. The data collected were analysed using mean, standard deviation, t-test and correlation analysis.

\section{RESULTS}

Research Hypothesis 1: There is no statistically significant difference between the mean score of students taught with collaborative inquiry method and traditional method.

Table 1 below showed that the mean score of the total number of students in collaborative teaching method (14.6) was greater than the mean score of the total number of students in the traditional teaching method (10.64). This is an indication that students performed better in collaborative inquiry teaching method than the traditional teaching method.

Table 1: Comparison of Collaborative and Traditional Teaching Methods' Mean Scores

\begin{tabular}{|c|c|c|c|c|c|c|}
\hline \multirow{2}{*}{$\begin{array}{c}\text { Teaching } \\
\text { Methods }\end{array}$} & \multicolumn{2}{|c|}{ Male } & \multicolumn{2}{c|}{ Female } & \multicolumn{2}{c|}{ Total } \\
\cline { 2 - 7 } & No: & $\begin{array}{c}\text { Mean }(\mathrm{x} \\
)\end{array}$ & $\begin{array}{c}\mathrm{N} \\
\mathrm{O}\end{array}$ & $\begin{array}{c}\text { Mean }(\mathrm{x} \\
\text { ) }\end{array}$ & No & Mean(x) \\
\hline Collaborative & 15 & 15.80 & 10 & 12.8 & 25 & 14.6 \\
\hline Traditional & 15 & 11.07 & 10 & 10.0 & 25 & 10.64 \\
\hline
\end{tabular}

In table 2 , the calculated $\mathrm{t}(4.46)$ is greater than the table $\mathrm{t}(2.01)$. Hence, this shows that there was a significant difference between the mean scores of students taught with collaborative inquiry method and traditional method of teaching. This is an indication that the students performed better in collaborative method than the traditional method.

Table 2: T-Test Analysis of the Performance of Students in Collaborative and Traditional Teaching Methods

\begin{tabular}{|c|c|c|c|c|c|c|c|}
\hline $\begin{array}{c}\text { Teaching } \\
\text { Methods }\end{array}$ & Number & Mean(x) & $\begin{array}{c}\text { Standard } \\
\text { Deviation }\end{array}$ & DF & TC & $\begin{array}{c}\text { T- } \\
\text { tab }\end{array}$ & Remarks \\
\hline Collaborative & 25 & 14.60 & 3.30 & \multirow{2}{*}{48} & 4.46 & 2.01 & $\begin{array}{c}\text { Significant } \\
\mathrm{P}<0.05\end{array}$ \\
\cline { 1 - 5 } Traditional & 25 & 10.64 & 2.97 & \multirow{2}{*}{40.97} & \\
\hline
\end{tabular}

Research Hypothesis 2: There is no statistically significant difference between the mean scores of male and female students exposed to the collaborative inquiry method.

In table 3 below, the calculated $\mathrm{t}(2.57)$ is greater than the table $\mathrm{t}(2.07)$. Hence, the research hypothesis 2 was rejected. The findings showed that there is significant difference between the mean scores of male and female students exposed to the collaborative teaching method. This indicates that the male students performed better than their female counterpart in Physics.

Table 3: Analysis of the Performance of Male and Female Students in the Collaborative Teaching Method

\begin{tabular}{|c|c|c|c|c|c|c|c|}
\hline $\begin{array}{c}\text { Collaborative } \\
\text { Teaching } \\
\text { Method }\end{array}$ & Number & Mean(x) & $\begin{array}{c}\text { Standard } \\
\text { Deviation }\end{array}$ & DF & TC & $\begin{array}{c}\text { T- } \\
\text { tab }\end{array}$ & Remarks \\
\cline { 1 - 5 } Male & 15 & 15.8 & 3.10 & 23 & 2.57 & 2.07 & $\begin{array}{c}\text { Significant } \\
\mathrm{P}<0.05\end{array}$ \\
\cline { 1 - 5 } Female & 10 & 12.8 & 2.68 & 23 & \\
\hline
\end{tabular}




\section{DISCUSSION}

Table 1 gives the comparison of mean scores of collaborative and traditional teaching methods. The mean scores of the total number of students in collaborative teaching method (14.6) was greater than the mean score of the total number of students in the traditional method (10.64). This is an indication that the students performed better in collaborative inquiry method than the traditional method of teaching as shown in figures 1 and 2. The first hypothesis verified whether there is difference between the mean score of students taught with collaborative inquiry method and traditional method. Rueda and colleagues [19], stated that inquiry-based method emphasis on "findings of knowledge" that are often ignored by traditional teaching curricular.

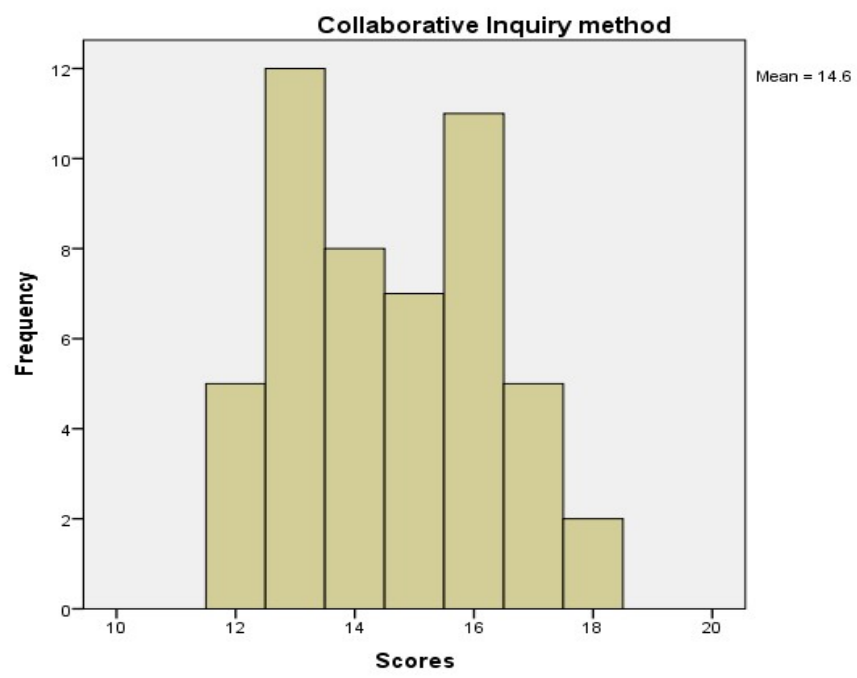

Figure 1: Mean Score of Students in the Collaborative Inquiry Learning Group

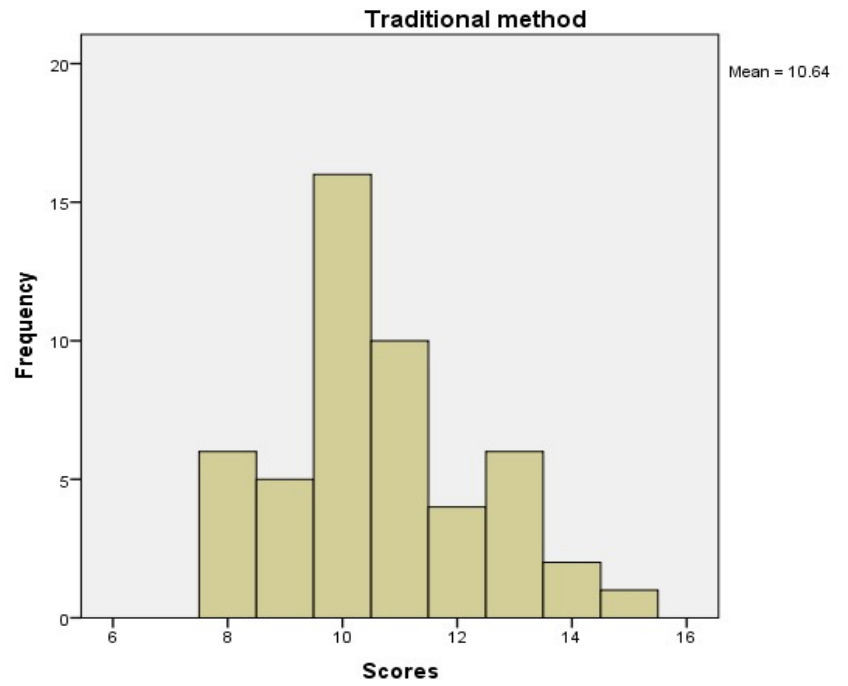

Figure 2: Mean Score of Students in the Traditional Learning Group

McKeachie [20] emphasized that; cognitively, collaborative inquiry method provides an opportunity for elaboration putting material into one's own words as well as a change to begin using the language of the discipline. This corroborate researchers like Miller, Imrie and Cox [16] which stated that "the problem can be solved by a small team of students, none of whom possesses the knowledge or skills to solve the problem alone, yet each of whom is able to contribute to the final product".

From table 2, it was seen that the calculated $\mathrm{t}(4.46)$ was greater than that of table $t(2.01)$, which implies that "there is significant difference between the mean score of students taught with collaborative inquiry method and traditional method. It was shown that students performed better in collaborative inquiry method than the traditional method.

The second hypothesis shows that there is significant difference between the mean scores of male and female students exposed to the collaborative inquiry method. From table 3 , the findings were buttressed with the findings made by Banks and colleagues [21] indicating that gender difference has a great influence on students' achievement in Physics, while Begley [22] and Callas [23], opined that "male students have better performance than female in Senior Secondary School Mathematics".

The calculated $t(2.57)$ was greater than table $t(2.07)$ which indicates that "there is a significant difference between the mean score of male and female students exposed to collaborative inquiry learning method. This indicates that male students performed better than their female counterpart in Physics. Male students had a mean score of (15.8) and standard deviation of (3.10) while female students had a mean score of (12.8) and standard deviation of (2.68). It was observed that there was a significant difference in the performance of male and female students in Physics as shown in figure 3 below.

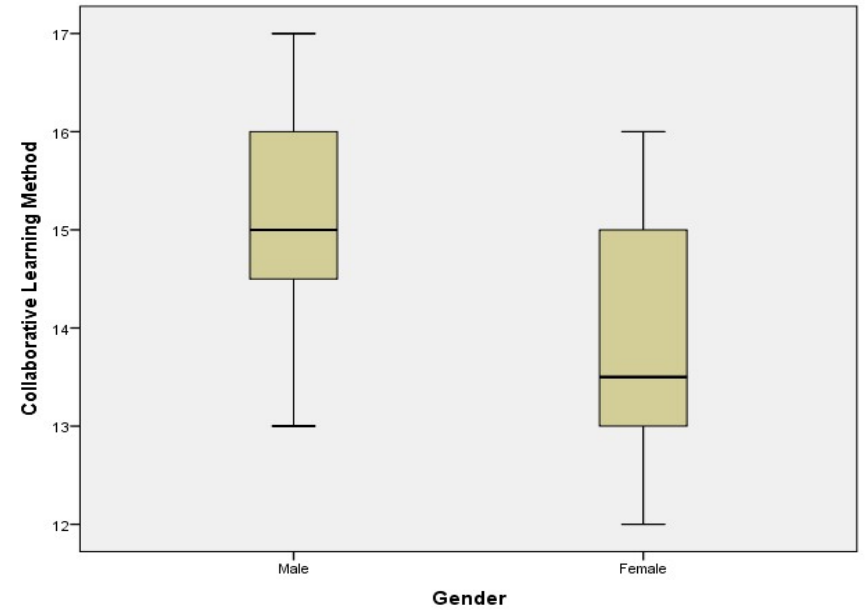

Figure 3: Performance Based on Gender in Collaborative Inquiry Learning

\section{CONCLUSSION}

In conclusion, it was observed that the better of the two teaching methods is the collaborative inquiry method because 
the students performed better in it and thus, allows the students to engage with subject matter in any discipline. It also affords the students the opportunity to explore academic content by posing, investigating and answering questions.

\section{LIMITATION OF THE STUDY}

This study is limited to two secondary schools and it should be extended to both public and private secondary schools in other states of the federation. However, other researchers could carry out the study in order to ensure a valid generalization of the findings, other interested researchers could work in tertiary institutions for valid generalization.

\section{RECOMMENDATIONS}

a) Students should be engaged in exploring, investigating and answering questions through the use of collaborative inquiry method in the teaching of Physics in order to enhance a better performance.

b) Government should provide adequate and conducive environment as well as learning and instructional materials for both the students and the teachers respectively.

c) Cooperate organizations should play their social responsibilities roles' in contributing to the socioeconomic development of education.

d) Collaborative inquiry teaching method should be adopted by Physics instructors so as to arouse the students' interest in Physics.

\section{CONFLICT OF INTEREST}

The authors declared no conflict of interest.

\section{FINANCIAL DISCLOSURE}

The authors declared that this study received no financial grant.

\section{AUTHORS CONTRIBUTIONS}

Alaba Tolulope Agbele 60\%, Emmanuel Akinbami Oyelade $18 \%$, Victor Shegun Oluwatuyi 22\%

\section{REFERENCES}

[1]. McLeod, S., (2007). Maslow's hierarchy of needs. Simply psychology, 1, pp.1-8.

[2]. Eade, D., (1997). Capacity-building: An approach to peoplecentred development. Oxfam.

[3]. Roseland, M., (2012). Toward sustainable communities: Solutions for citizens and their governments. New Society Publishers.
[4]. Hart, S.L. and Milstein, M.B., (2003). Creating sustainable value. Academy of Management Perspectives, 17(2), pp.56-67.

[5]. Symington, A.J. and Pinelli, J., (2006). Developmental care for promoting development and preventing morbidity in preterm infants. Cochrane database of systematic reviews, (2).

[6]. McDermott, L.C. and Redish, E.F., (1999). Resource letter: PER1: Physics education research. American journal of physics, 67(9), pp.755-767.

[7]. Henkel, M., (2005). Academic identity and autonomy in a changing policy environment. Higher education, 49(1), pp.155176.

[8]. Appelquist and Shapper (2001): Year 2001 Report on Physics: American Journal of "Physics for Today" United States of America.

[9]. Tuminaro, J. and Redish, E.F., (2004). Understanding students' poor performance on mathematical problem solving in physics. In AIP Conference Proceedings (Vol. 720, No. 1, pp. 113-116). American Institute of Physics.

[10]. Brunner, J. S. (1961) "The Act of Discovery". Harvard Educational Review 31(1): 21-32

[11]. Llewellyn, D (2001). Inquire Within: Implementation of Inquirybased Science Standards, Corwin Press. Uk

[12]. Alao, J. D. (2009). The Concept of ICT in Modern Education

[13]. Appelquist and Shapper (2001). Year 2001 Report on Physics: American Journal of "Physics for Today" United States of America.

[14]. Thornton, R. K \& Sokoloff, D. R (1998). "Assessing Students Learning of Newton's laws": The force and motion conceptual evaluation and the evaluation of active learning laboratory and lecture curricula, American Journal of Physics Pp66:338-352, Washington D.C, Doult Press.

[15]. Negata and Ponkowski (1981). "Collaborative Learning Skills": National Research Council: National Science Education Standards, Washington D. C. National Academy Press.

[16]. Miller, Imrie and Cox (2009). The Concept of collaborative Teaching. Essential Research for lasting reform. "Journal of Research in Science Teaching 36(6) p. 631-645

[17]. Herr, N. (2008). The source book for Teaching Science: San Francisco, John Bewey Publications.

[18]. Johnson, D. W., Johnson, R. T and Smith, K. A. (1991). Cooperative Learning: Increasing College Faculty Instructional Productivity. ASHE-ERIC Higher Education Reports N0 4, George Washington University, One Dupont Circle, Suite 630, Washington, DC 20036-1183; 1991.

[19]. Rueda, R., Gallego, M.A. and Moll, L.C., (2000). The least restrictive environment: A place or a context?.Remedial and Special Education, 21(2), pp.70-78.

[20]. McKeachie, W.J., (1994). Student motivation, cognition, and learning: Essays in honor of Wilbert J. McKeachie. Routledge.

[21]. Banks, J., Cochran-Smith, M., Moll, L., Richert, A., Zeichner, K., LePage, P., Darling-Hammond, L., Duffy, H. and McDonald, M., (2005). Teaching diverse learners. Preparing teachers for a changing world: What teachers should learn and be able to do, 2005, pp.232-274.

[22]. Begley, S (1988). “Closing the gender gap”. New York: III(15) 73

[23]. Callas, D., (1993). Differences in mathematics achievement between males and females. Community college review, 21(3), p.62-67. 